\title{
A IMPORTÂNCIA DO HORMÔNIO D NAS INTERCORRÊNCIAS ESTÉTICAS E SEUS DECLÍNIOS NA PELE
}

\section{ARTIGO DE REVISÃO}

OLIVEIRA, Fabíola Santos Lima De ${ }^{1}$

FIGUEIREDO, Cristiane Santos Silva e Silva ${ }^{2}$

BARROSO, Wermerson Assunção ${ }^{3}$

FREITAS, Milena Sousa ${ }^{4}$

SARAIVA, Cinara Wirtzbiki ${ }^{5}$

OLIVEIRA, Fabíola Santos Lima De. Et al. A importância do hormônio D nas intercorrências estéticas e seus declínios na pele. Revista Científica Multidisciplinar Núcleo do Conhecimento. Ano 05, Ed. 10, Vol. 21, pp. 133-145. Outubro de 2020. ISSN: 2448-0959, Link de acesso: https://www.nucleodoconhecimento.com.br/saude/hormonio-d

1 Especialização em Massoterapia Oriental. Graduação em andamento em Biomedicina. Graduação em Bacharel Em Serviço Social.

2 Orientadora. Doutorado em Biodiversidade e Biotecnologia da Amazônia LegalBIONORTE. Mestrado em Biologia Parasitária. Graduação em farmácia. Graduação em Pedagogia.

${ }^{3}$ Doutorado em Programa de Pós-Graduação em Ciências Médicas. Mestrado em Programa de Pós-Graduação em Ciências Médicas. Graduação em Farmácia.

4 Mestrado em Doenças Tropicais. Especialização em andamento em Biologia Molecular E Citogenética. Especialização em hematologia. Graduação em biomedicina.

${ }^{5}$ Mestrado profissional em andamento em Ciências Ambientais. Especialização em Gestão De Programas De Serviços De Saúde. Graduação em Fisioterapia. 


\section{RESUMO}

O hormônio D é uma substância endógena obtida principalmente pela exposição solar ultravioleta (UVB), sendo a sua deficiência e disfunção assintomática e está associada a inúmeras intercorrências estéticas conhecidas mundialmente. Tais situações podem ser revertidas através da prevenção com Vitamina $D$ endogenamente ou por suplementação alimentar, para que os níveis de produção desse hormônio sejam normalizados no organismo. O aumento da mortalidade ocasionado por essas intercorrências tem trazido grande inquietação para a sociedade científica atual, visto que a insuficiência do hormônio $D$ está correlacionada com alterações de pele. Isso tem evidenciado o começo das doenças autoimune, envelhecimento precoce, diabete mellitus tipo 2, obesidade e neoplasias cutâneas, tornando-se um dos focos de pesquisas nos últimos anos. Este estudo visa aumentar o conhecimento sobre a vitamina $D$, bem como as consequências de seus níveis insuficientes, além de demonstrar que o hormônio $D$, presente no organismo em seu nível ideal, é efetivo na prevenção de doenças autoimunes, cutâneas e na melhora da resposta imunológica e sistêmica.

Palavras-chave: Hormônio D, pele, intercorrências, radiação UVB, hipovitaminose.

\section{INTRODUÇÃO}

O hormônio $D$, também denominado Vitamina $D$, é considerado uma substância lipossolúvel que atua juntamente com o paratormônio (PTH) na regulação da homeostase do cálcio e no metabolismo ósseo (MAEDA, 2014). O hormônio se apresenta de duas formas, como Vitamina D2 ou ergocalciferol e Vitamina D3 ou colecalciferol (CASTRO, 2011). A forma de obtenção é através dos raios UVB, que é a nossa principal fonte, ou através da alimentação. O nosso DNA possui a capacidade de receber estas substâncias para produzir a sua síntese para que ocorram as ações metabólicas produzidas endogenamente (BARBOSA, et al, 2018).

A vitamina D2 é produzida a partir de esteroide fúngico, o ergosterol, e usada como suplemento alimentar, por apresentar pouca disponibilidade nos alimentos. A síntese 
da vitamina D3 ocorre na pele pela ação dos raios UVB a partir do precursor 7dehidrocolesterol, e pode ser encontrada em alimentos como óleo de peixe, gema de ovo, entre outros (JUNIOR, 2011).

Após a ingestão do hormônio $\mathrm{D}$ se inicia o processo de metabolismo, com a síntese do mesmo, que, em seguida, será transportado até o fígado, onde será hidrolisado em carbono 25 para sua conversão em 25-hidroxi-vitamina $D(25(\mathrm{OH}) \mathrm{VD})$, que é a forma circulante da vitamina. Na etapa seguinte, a $25(\mathrm{OH}) \mathrm{VD}$ sofrerá uma nova hidroxilação para produzir sua forma ativa, a 1,25 dihidroxi-vitamina $D$ 1,25(OH)2D, a qual não apresenta estoque corporal considerável (SILVA, 2008).

A deficiência do Hormônio $D$ é uma disfunção assintomática que vem sendo relatada na fisiopatologia e progressão de diversas doenças cardiovasculares, diabetes e alguns tipos de cânceres. Além disso, a insuficiência desses níveis tem influenciado inúmeras intercorrências estéticas, causando desequilíbrios na saúde da pele e no DNA. Entretanto, a presença do hormônio $D$ tem importante participação na qualidade da pele, podendo ajudar no nível de hidratação, colágeno e elastina, que são proteínas naturais da nossa pele (JEFFERY et al., 2016).

A anamnese deve ser minuciosamente detalhada para a verificação de fatores de comprometimento da pele nos procedimentos estéticos. Dentre estes deve-se investigar o histórico para saber o nível de hormônio $D$, para entender a resposta de cicatrizes e diabetes mellitus, a fim de se evitar o desenvolvimento de complicações imediatas e tardias da pele deste paciente. A parte clínica dos procedimentos estéticos promove qualidade da pele e do paciente, evitando intercorrências estéticas (FURTADO et al, 2020).

A ação do hormônio D é fundamental para o sistema imune, o qual é responsável pela defesa do nosso organismo, estimulando a proliferação de células de defesa (ZASLOFF, 2005). Elas são transportadas para a superfície através de vesículas, sendo importantes na resposta imune de linfócitos B na produção de anticorpos e na atividade de células natural killer, bem como na função dos linfócitos $T$ e dos mecanismos de defesa inata e adaptativa. Regulam o equilíbrio de sódio e água, 
controlando o volume sanguíneo da pressão arterial, preservam as concentrações do líquido intracelular do cálcio e fosfato e regulam o balanço energético através do armazenando energia das demandas metabólicas (RAFAELLI et al, 2015). Jeffery et al., (2016) também relata em seu trabalho que o hormônio D em seu nível ideal tornase efetivo na prevenção de doenças cutâneas, melhorando a resposta imunológica e sistêmica.

Segundo os diversos estudos, a falta do hormônio $D$ tem levado a inúmeros fatores de riscos identificados nas doenças autoimunes, que ocasionam o câncer de pele, tumor, envelhecimento precoce, melasma e rugas (BARBOSA et al, 2018). Deste modo, um levantamento de dados referentes à falta de vitamina $\mathrm{D} e$, principalmente, aos modos de prevenção, se faz necessário em virtude do alto índice de ocorrência entre as crianças, mulheres, homens e idosos. Os dados poderão ser utilizados para realização de medidas preventivas, podendo assim possibilitar um melhor entendimento da população em geral.

\section{METODOLOGIA}

O presente trabalho consiste em uma revisão de literatura acerca do tema, a partir de artigos científicos disponíveis nas bases de dados eletrônicas PubMed, Scientific Electronic Library Online (SciELO), Web of Science, Google Acadêmico e Portal Periódicos, publicados em língua portuguesa e inglesa, entre os anos de 2000 e 2020. As palavras-chave utilizadas foram as seguintes: Hormônio D; Pele; Intercorrências; Radiação UVB; Hipovitaminose. Os critérios de inclusão adotados foram de proximidade com o tema e artigos publicados entre os anos acima citados. E os critérios de exclusão foram os artigos que não estavam relacionados com o objetivo deste estudo e não estavam inseridos no período de consulta. Ao final, foram selecionados nesse levantamento 58 artigos para leitura e análise, utilizando-se o total de 28 artigos eleitos para a realização deste trabalho e acessamos o texto completo de todas as referências relevantes a partir dos resultados da pesquisa. 


\section{RESULTADOS E DISCUSSÃO}

\subsection{HORMÔNIO D E METABOLISMO}

A exposição diária da pele humana às agressões externas e internas acabaram por determinar, fisiologicamente, este órgão como uma barreira física para atuar na proteção e regulação da temperatura corporal e na absorção de substâncias. Apesar de possibilitar a ocorrência de queimaduras e neoplasias cutâneas, alguns benefícios como a produção do hormônio $D$ também estão relacionados com essa exposição a agentes externos (BATISTA, 2013).

O hormônio D possui um papel importante na regulação da fisiologia osteomineral, principalmente no metabolismo do cálcio, e na homeostase de diversos processos no organismo. Esses processos envolvem desde a produção natural de antibióticos pelas células de defesa, controle da pressão arterial, até a multiplicação e diferenciação celular, com função antioncogênica. O metabolismo deste hormônio ocorre inicialmente através da exposição solar, pela ação da luz ultravioleta, que isomeriza a molécula de 7-dehidrocolesterol existente nas camadas mais profundas da epiderme (CASTRO, 2011).

A primeira etapa do processo é iniciada com o transporte do colecalciferol pela DBP (proteína ligadora de vitamina $\mathrm{D}$ ) até o fígado, para ser estocado e ativado pelas glândulas paratireoides, que produzem o paratormônio. Para a realização dos processos metabólicos e hormonais, o carbono 25 é hidroxilado no fígado para produzir o 25 hidroxivitamina $\mathrm{D}(25(\mathrm{OH}) \mathrm{D})$, que, em seguida, é convertido em calcitriol ou 1,25 diidroxi-vitamina $D[1,25(\mathrm{OH}) 2 \mathrm{D}]$ nos rins, sendo biotransformada em hormônio D, em sua forma ativa ou inativa (SILVA; BARBOSA, 2020).

Para que se inicie a ativação da vitamina $D$ é necessário se atentar a quantidade $e$ intensidade da luz solar direta recebida pelo individuo, assim como para a quantidade de melanina na pele. Semelhante a isso, Looker (2002) evidenciou em seu estudo sobre o status sérico de 25-hidroxivitamina $D$, que a menor quantidade de 25(IH)D é atribuída aos indivíduos de pele negra quando comparados aos caucasianos. Por isso, 
os indivíduos negros necessitam de um tempo maior de exposição solar. Ainda, corroborando com as informações, Castro (2011) aponta que os idosos demandam uma atenção especial durante a etapa inicial da ativação desse hormônio por apresentarem afinamento da pele, ocasionando diminuição dos níveis de 7DHC, devido ao processo natural de envelhecimento.

\subsection{DEFICIÊNCIA DO HORMÔNIO D}

Um estudo sobre as recomendações para o diagnóstico e tratamento da hipovitaminose $D$ mostra que a vitamina $D$ é essencial para o metabolismo ósseo e está relacionada com a patogênese de várias doenças, sendo uma questão de saúde global. Além de apontar que indivíduos como os idosos, mulheres na pós-menopausa e adolescentes apresentam maior suscetibilidade para o desenvolvimento de problema por ocorrência de hipovitaminose $D$. Dentre os fatores relacionados às baixas concentrações dessa vitamina no soro, temos a exposição solar, idade, prática de atividades físicas ao ar livre, suplementação, estação do ano, latitudes baixas e residir em regiões litorâneas e ensolaradas, além do envelhecimento (MAEDA et al, 2014).

Lee (2012); Pittaway (2013) e Al-Mutairi (2012) corroborando com os estudos, ainda acrescentam que já existe um conhecimento popular bem definido sobre os prejuízos causados pela exposição a luz solar, podendo estes acarretar problemas nos níveis da vitamina $D$, visto que essa exposição é necessária para o metabolismo desse hormônio.

A suplementação da vitamina $D$ se dá pela ingestão oral das suas duas formas: a vitamina D2 e vitamina D3. Sendo esta última a mais importante por participar do metabolismo direto desse hormônio pela ação dos raios ultravioleta. Ainda, nota-se que a dosagem usada na suplementação sofre variação devido a diversos fatores, como o clima, alimentação, localização geográfica e perfil de cada população (LACERDA, 2015). 
Segundo Bandeira (2006), a estação do ano e as latitudes são importantes fatores relacionados ao desenvolvimento de hipovitaminose $\mathrm{D}$, pois a exposição aos raios solares é fundamental para a formação da vitamina. Lacerda (2015) aponta que durante o período do outono e inverno tem-se a ocorrência de mais casos de hipovitaminose $\mathrm{D}$, por serem os meses com menos incidência de raios solares. Além de considerar que locais com climas tropicais e subtropicais obtêm maior quantidade e intensidade de radiação solar, por períodos maiores, quando comparadas com latitudes mais altas.

O envelhecimento é outro fator de risco para hipovitaminose $D$, devido a capacidade reduzida da pele sintetizar o precursor pró-vitamina D. A alimentação inadequada, menor exposição aos raios solares, absorção gastrointestinal reduzida e o uso elevado de fármacos também interferem no metabolismo da vitamina D (SARAIVA, 2007).

A insuficiência do hormônio $D$ também está associada a outras variáveis fisiológicas: o envelhecimento biológico, impossibilitando a chegada das respostas aos receptores do núcleo da celular; a energia mitocondrial, anulando assim a funcionalidade da formação celular e tecidual; e com o sistema imunológico, na resposta inata e na expressão do receptor para a distribuição em uma ampla variedade de células, tecidos e órgãos, como a pele (JEFFERY et al, 2016).

BARBOSA et al, (2018) relata que a falta de radiações eletromagnéticas leva ao desequilíbrio da pele. Pode-se comprometer a função endrócina do indivíduo, a qual tem papel importante na coordenação das atividades celulares, manutenção e hemostasia desde início da nossa vida embrionária, assegurando constantemente a função das nossas células.

Ruivo (2014) relata em seu estudo sobre o envelhecimento cutâneo que a deficiência do hormônio $\mathrm{D}$ compromete a atividade mitocondrial celular, podendo ocasionar o envelhecimento precoce da pele com o aparecimento de rugas estáticas, manchas e doenças de pele. Os estudos encontrados evidenciam que tratamentos estéticos sem o estímulo à síntese da matéria-prima do hormônio $D$ não têm eficácia nestas 
intercorrências, por não favorecer o sequenciamento das cadeias de aminoácidos. Sendo estas necessárias para gerar lipoproteínas e formação de colágeno tipo I, bem como o fortalecimento da barreira pavimentosa. (DUARTE, 2012; CASTRO, 2011).

\subsection{HIPOVITAMINOSE D RELACIONADA ÀS INTERCORRÊNCIAS NA PELE}

De acordo com Teixeira (2010), o hormônio D tem participação no processo de divisão celular nas fases do ciclo celular, sugerindo uma justificativa na relação com o envelhecimento da pele, manchas e principalmente com os achados que relatam linhas estáticas em pacientes com baixos níveis de hormônio $D$.

Entre os fatores associados a absorção do hormônio $D$, tem-se a combinação de doses de radiação ultravioleta juntamente com o biotipo de pele, como responsáveis por $80 \%$ desse processo. Apesar de reduzir a absorção da vitamina, a melanina não possui capacidade para bloquear completamente esse processo, demandando, assim, um maior período de exposição solar para obtendo do hormônio D (HAACK, 2008). Concordante a isso, Armas (2007) afirma ainda que indivíduos de pele clara não necessitam de doses altas de radiação solar para o metabolismo desse hormônio. De acordo com o estudo de Bogh et al., (2011), o aumento da área corporal exposta pelos raios UVB pode alterar os níveis de absorção de vitamina $\mathrm{D}$, a partir da quantidade de melanina originada pelo indivíduo.

As intercorrências cutâneas são acometidas por fatores extrínsecos e intrínsecos, os quais são causados principalmente por falta de radiações na pele e de hormônio $D$. As manchas da pele e o envelhecimento precoce são declínios ocasionados por excesso de álcool, má alimentação, entre outras condições. Também entre os fatores extrínsecos, os músculos da expressão facial se inserem diretamente na pele, determinando tensão contínua mesmo em repouso. Ao longo do tempo eles produzem um alongamento do colágeno na direção da tração muscular (COIMBRA, 2014).

A exposição à radiação ultravioleta pode causar alterações no DNA dos melanócitos, resultando no risco de carcinogênese em novos melanócitos na infância. O período 
da infância e da adolescência são considerados críticos em relação à vulnerabilidade aos efeitos da exposição solar. Esse comportamento de exposição durante estes períodos da vida pode levar ao desenvolvimento do câncer não melanoma ou do melanoma maligno na vida adulta (CRIADO et al, 2012 apud BOMFIM, 2018)

Batista (2013) destaca que o câncer de pele não melanoma (CPNM) é considerado o tipo de neoplasia mais comum, englobando cerca de $90 \%$ dos tumores malignos primários da pele. O CPNM está diretamente associado aos indivíduos de pele branca e a exposição contínua às radiações solares. Ainda segundo esse autor, o melanoma maligno (MM) é responsável por pelo menos três quartos dos óbitos decorridos de câncer de pele, apesar de demonstrar prevalência em apenas 4\% das neoplasias malignas cutâneas. Esses casos estão relacionados à exposição solar intensa durante a infância, ocasionando problemas dérmicos como queimaduras e formação de bolhas, que necessitam de cuidados especiais imediatos.

\section{CONSIDERAÇÕES FINAIS}

Os resultados mostram que a deficiência do hormônio $D$ é um caso de saúde pública mundial, principalmente entre os grupos de risco. Além disso, é notório que o hormônio $D$, na pele, tem um papel importante na regulação das vias de síntese lipoproteicas exógenas e endógenas, na prevenção e regeneração da saúde da pele, prevenindo danos ocasionados nas intercorrências estéticas. No entanto, estudos ainda são necessários para determinar mais benefícios da reposição do hormônio $D$, em quais pacientes devemos mensurar a 25(OH)D e quais os valores de referência para considerar a eficácia nas ações de intercorrências acometidas na pele.

\section{REFERÊNCIAS BIBLIOGRÁFICAS}

AL-MUTAIRI N, ISSA B, NAIR V. Photoprotection and vitamin D status: a study on awareness, knowledge and attitude towards sun protection in general population from Kuwait, and its relation with vitamin D levels. Ind J Dermatol Venereol Leprol. 2012; 78(3):342-9. 
ARMAS LA. Ultraviolet-B radiation increases serum 25-hydroxyvitamin D levels: the effect of UVB dose and skin color. J Am Acad Dermatol. 2007;57(4):588-93.

BANDEIRA F. et al; Vitamin D Deficiency: A Global Perspective. Arquivo Brasileiro de Endocrinologia e Metabologia. 2006.

BATISTA, Thais et al. Avaliação dos cuidados de proteção solar e prevenção do câncer de pele em pré-escolares. Revista Paulista de Pediatria, v. 31, n. 1, p. 17-23, 2013.

BOGH MK, SCHMEDES AV, PHILIPSEN PA, THIEDEN E, WULF HC. Interdependence between body surface area and ultraviolet $B$ dose in vitamin $D$ production. Br J Dermatol. 2011;164(1):163-9.

BOMFIM SS, GIOTTO AC, SILVA AG. Câncer de pele: conhecendo e prevenindo a população. Rev. Cient. Sena Aires.2018; 7(3): 255-9.

CASTRO, Luiz Claudio Gonçalves de. O sistema endocrinológico vitamina D. Arquivos Brasileiros de Endocrinologia \& Metabologia, v. 55, n. 8, p. 566-575, 2011.

COIMBRA, D.D.; URIBE, N.C.; OLIVEIRA, B. S. "Quadralização facial” no processo do envelhecimento - Surg Cosmet Dermatol 2014;6(1):6571.

CRIADO PR, NAKANO MJ, PRADO OZN. Fotoproteção tópica na infância e na adolescência. Jornal de Pediatria. 2012; 88(3): 203-10.

DA SILVA, Ádria Rodrigues et al. 25-hidroxivitamina D e exposição solar: uma análise epidemiológica entre os estudantes de medicina/25-hidroxivitamina $D$ e exposição solar: uma análise epidemiológica entre os estudantes de medicina. Brazilian Journal of Development, v. 6, n. 2, p. 9239-9258, 2020.

DO NASCIMENTO BORGES, Ana Clara et al. Vitamin D linked to high blood pressure. Research, Society and Development, v. 9, n. 1, p. 110911691, 2020. 
DUARTE, Andresa Brito; MEJIA, Dayana Priscila Maia. A utilização da Radiofrequência como técnica de tratamento da flacidez corporal. Portal Biocursos, 2012.

FURTADO, Gisele Rosada Dônola et al. Necrose em ponta nasal e lábio superior após rinomodelação com ácido hialurônico-relato de caso.2020.

HAACK RL, HORTA BL, CESAR JA. Sunburn in young people: population- based study in Southern Brazil. Rev Saúde Pública. 2008;42(1):26-33.

JEFFERY, Louisa E.; RAZA, Karim; HEWISON, Martin. Vitamin D in rheumatoid arthritis-towards clinical application. Nature Reviews Rheumatology, v. 12, n. 4, p. 201, 2016.

JUNIOR, Edson Pedroza dos Santos et al. EPIDEMIOLOGIA DA DEFICIÊNCIA DE VITAMINA D. Rev Cient ITPAC 2011; 4 (3) Pub. 2

LEE SH, PARK SJ, KIM KM, LEE DJ, KIM WJ, PARK RW, JOO NS. Effect of sunlight exposure on serum 25-hydroxyvitamin d concentration in women with vitamin d deficiency: using ambulatory lux meter and sunlight exposure questionnaire. Korean J Fam Med. 2012; 33(6):381-9. 14.

LOOKER AC, DAWSON-HUGHES B, CALVO MS, GUNTER EW, SAHYOUN NR. Serum 25-hydroxyvitamin $D$ status of adolescents and adults in two seasonal subpopulations from NHANES III. Bone 2002;30:771-7.

MAEDA, Sergio Setsuo et al. Recomendações da Sociedade Brasileira de Endocrinologia e Metabologia (SBEM) para o diagnóstico e tratamento da hipovitaminose D. Arquivos Brasileiros de Endocrinologia \& Metabologia, v. 58, n. 5, p. 411-433, 2014.

PITTAWAY JK, AHUJA KD, BECKETT JM, BIRD ML, ROBERTSON IK, BALL MJ. MAKE Vitamin D While the Sun Shines, Take Supplements When it Doesn't: A 
Longitudinal, Observational Study of Older Adults in Tasmania, Australia. PLoS One. 2013; 8(3):1-9.

RAFAELLI, Rafael Algusto et al. Influência da vitamina $\mathbf{D}$ nas doenças endocrinometabólicas. Semina: Ciências Biológicas e da saúde, v. 36, n. 1Supl, p. 333-348, 2015.

RUIVO, Adriana Pessoa. Envelhecimento Cutâneo: fatores influentes, ingredientes ativos e estratégias de veiculação. 2014. Tese de Doutorado. [sn].

SARAIVA, G.L; Cendoroglo, M.S et al: Prevalência da deficiência, incidência de vitamina $D$ e hiperparatiroidismo secundário em idosos institucionalizados $e$ moradores na comunidade da cidade de São Paulo, Brasil. Revista Brasileira de Endocrinologia e Metabologia. 2007.

SILVA, Bárbara C. Carvalho et al. Prevalência de deficiência e insuficiência de vitamina $D$ e sua correlação com PTH, marcadores de remodelação óssea e densidade mineral óssea, em pacientes ambulatoriais. Arquivos Brasileiros de Endocrinologia \& Metabologia, v. 52, n. 3, p. 482-488, 2008.

SILVA, Anabela Barreto; BARBOSA, Maria João. Suplementação de vitamina D na prevenção de quedas e fraturas em idosos: uma revisão baseada na evidência. Revista Portuguesa de Medicina Geral e Familiar, v. 36, n. 3, p. 277-287, 2020.

SPECK, Milena Moreira; ZANETI, Larissa Aparecida. Revisão sistemática: nutricosméticos utilizados nos tratamentos das disfunções estéticas. Tecnologia em Cosmetologia e Estética-Tubarão, 2019.

TEIXEIRA, Ilka Nicéia D.; GUARIENTO, Maria Elena. Biologia do envelhecimento: teorias, mecanismos e perspectivas. Ciência \& Saúde Coletiva, v. 15, p. 2845-2857, 2010. 
ZASLOFF, Michael. Sunlight, vitamin D, and the innate immune defenses of the human skin. Journal of Investigative Dermatology, v. 125, n. 5, p. xvi, 2005.

Enviado: Outubro, 2020.

Aprovado: Outubro, 2020. 